\title{
REVIEW
}

\section{Ambulatory arterial stiffness in chronic kidney disease: a methodological review}

\begin{abstract}
Andrea Lászlón ${ }^{1}$, György Reusz ${ }^{2}$ and János Nemcsik ${ }^{1,3,4}$
Cardiovascular mortality is the leading cause of death in chronic kidney disease (CKD) and end-stage renal disease (ESRD). This can be explained in part by an increased and progressive calcification of the medial layer of the large arteries leading to arterial stiffening. The prognostic value of measurements of arterial stiffness, especially pulse wave velocity (PWV), in the general population and in CKD and ESRD patients is high, and is above that of traditional risk factors with respect to cardiovascular outcome. In recent years, as an alternative to office measurements, methods for monitoring ambulatory arterial stiffness have been developed. The ambulatory arterial stiffness index (AASI) allows derivation of a parameter from ambulatory blood pressure measurements; however, doubts have emerged about the usefulness of this parameter. Recently, new oscillometric methodologies using simple brachial cuffs, such as Mobil-0-Graph, Vasotens or Arteriograph 24, have been introduced. They measure parameters of 24-h arterial stiffness including PWV, augmentation index and central blood pressure. This enables study of the 24-h variability of these parameters, which will hopefully lead to better cardiovascular risk stratification and improved cardiovascular outcomes of patients. Our review summarizes the present data and future directions of AASI and the methods for monitoring oscillometric 24-h stiffness in different patient populations and especially in CKD. Hypertension Research (2016) 39, 192-198; doi:10.1038/hr.2015.137; published online 3 December 2015
\end{abstract}

Keywords: ambulatory arterial stiffness index; ambulatory arterial stiffness monitoring; ambulatory blood pressure monitoring; chronic kidney disease

\section{THE IMPORTANCE OF ARTERIAL STIFFNESS MEASUREMENT IN CHRONIC KIDNEY DISEASE}

Cardiovascular disease is the leading cause of morbidity and mortality in chronic kidney disease (CKD) as well as in end-stage renal disease (ESRD). ${ }^{1,2}$ With the spread of noninvasive arterial elasticity measuring devices over the past two decades, increasing evidence has demonstrated the strong prognostic value of different arterial stiffness parameters, especially aortic pulse wave velocity (PWV) and augmentation index (Aix), in CKD and ESRD. ${ }^{3,4}$ In our previous review, we described how such pathophysiological pathways could potentially lead to an increased arterial stiffening in CKD. ${ }^{5}$ These pathophysiological conditions are summarized in Table 1.

There are numerous devices with different methodologies that are able to measure arterial stiffness noninvasively. The PWV values of some of these devices have already been shown to predict cardiovascular mortality in different patient populations; for the remaining devices, the results of follow-up studies are still required. ${ }^{6}$ In hypertension, carotid-femoral PWV with a cutoff value of $10 \mathrm{~m} \mathrm{~s}^{-1}$ has already been included in the European hypertension guideline as a method for identifying asymptomatic organ damage. ${ }^{7}$ Until now the 'gold standard' methods have involved the use of a tonometer or a mechanotransducer to evaluate carotid and femoral pulse waves. These devices require a skilled operator to produce measurements of acceptable quality, especially in obese patients. Furthermore, manipulation in the inguinal region can be uncomfortable and aggravating for the patient. Therefore, new and less operator-dependent methods may provide an opportunity for the spread of arterial stiffness measurements to further develop the cardiovascular risk stratification of patients. Here, we focus on methods that are associated with ambulatory blood pressure monitoring (ABPM). First, we review the ambulatory arterial stiffness index (AASI), which can be derived from blood pressure data of ABPM. After this, we discuss oscillometric methods that are accompanied by ABPM and determine the 24-h profile of arterial stiffness and central blood pressure. We focus on PWV and Aix as arterial stiffness parameters, and central blood pressure and pulse pressure amplification reflect central hemodynamic properties. We do not discuss additional parameters such as total vascular resistance, reflection magnitude or left ventricular ejection time, which are also provided by some of these devices but for which there is less proof of cardiovascular predictive value. Recent results in CKD patients and future directions will be reviewed as well.

AASI: EVIDENCE IN CARDIOVASCULAR RISK STRATIFICATION AASI, derived from ABPM measurements, was introduced by Li et al. ${ }^{8}$ in 2006 and is defined as 1 minus the slope of diastolic on systolic

${ }^{1}$ Department of Family Medicine Semmelweis University Budapest, Budapest, Hungary; ${ }^{2}$ First Department of Pediatrics, Semmelweis University, Budapest, Hungary; ${ }^{3}$ Health Service of Zugló (ZESZ), Budapest, Hungary and ${ }^{4}$ Department of Emergency Medicine, Uzsoki Hospital, Budapest, Hungary

Correspondence: Dr J Nemcsik, Department of Family Medicine, Semmelweis University, Kútvölgyi str. 4, Budapest 1125, Hungary.

E-mail: janos.nemcsik@gmail.com

Received 27 June 2015; revised 27 September 2015; accepted 6 October 2015; published online 3 December 2015 


\section{Table 1 Pathogenesis of arterial stiffening in $C K D^{5}$}

1. Increased matrix metalloproteinase production lead to alterations in the extracellular matrix

2. Accumulation of advanced glycation end-products modify collagen and generate reactive oxygen species and nitric oxide deactivation

3. Presence of endothelial dysfunction owing to the reduced clearance of uremic toxins, like asymmetrical dimethylarginin, an inhibitor of nitric oxide synthase

4. The powerful vasoconstrictor endothelin, which receptor antagonist in non-diabetic CKD reduces proteinuria and arterial stiffness independently of blood pressure lowering

5. Overactivation of the renin-angiotensin-aldosterone system, as its inhibition in hemodialysis patients with decreased PWV was associated with reduced all-cause and cardiovascular mortality

6. Chronic inflammation through the inflammatory degradation of elastin and many other mechanisms

7. Hyperphosphatemia, hypercalcemia, high intake of calcium (by calcium-containing phosphate binders) lead to media calcification and arteriosclerosis

8. 'CKD-bone mineral disorder': the strong relationship between vascular calcification and bone metabolism alterations in CKD with the active involvement of regulators of osteogenesis, like osteoprotegrin, matrix Gla protein, fetuin-A, bone morphogenic protein 7, fibroblast growth factor 23

pressure. Li et al. ${ }^{8}$ have found AASI to be correlated with the central and peripheral systolic indexes, central pulse pressures and PWV.

AASI has been found to be associated with numerous cardiovascular risk factors and target organ damage. Leoncini et al. have investigated 188 patients with primary hypertension, finding that AASI was positively related to triglycerides, urinary albumin excretion and carotid intima-media thickness. Furthermore, each s.d. increase in AASI resulted in an approximately two times higher risk of microalbuminuria, left ventricular hypertrophy and carotid abnormalities and doubled the risk of the occurrence of one or more signs of target organ damage. ${ }^{9}$ Another study has found that AASI was positively correlated with carotid intima-media thickness and inversely related to ankle/brachial index in hypertension. ${ }^{10}$

Follow-up studies have demonstrated the prognostic value of AASI for cardiovascular events and mortality. In a cohort of 11291 patients of the Dublin Outcome Study with 5.3 years follow-up, Dolan et al. have shown that AASI predicts cardiovascular mortality better than does pulse pressure. Whereas an elevated pulse pressure predicted cardiac mortality in hypertensive patients, elevated values of AASI were able to predict cardiovascular and stroke mortality in both normotensive and hypertensive patients. ${ }^{11}$ Other studies have observed that AASI carries prognostic information, it was found to be a predictor of cardiovascular morbidity and mortality in a cohort of 547 patients with resistant hypertension; ${ }^{12}$ in the general population, it was found to be a better predictor of cardiovascular and stroke mortality than pulse pressure. ${ }^{13}$

There are also data on the relationship between the glomerular filtration rate (GFR) and AASI. Mulé et al. ${ }^{14}$ have shown that AASI is inversely correlated with GFR in arterial hypertension. A negative correlation between AASI and GFR has also been observed in another study with 554 hypertensive patients. ${ }^{10}$ It has also been found that AASI is positively correlated with urinary albumin excretion and is negatively related to estimated creatinine clearance in recently diagnosed and untreated hypertensive patients. Furthermore, AASI is a better predictor of GFR decline than 24-h pulse pressure measurement. ${ }^{9,15}$

The reproducibility of AASI measured in stage 2-5 CKD patients was moderate but acceptable. ${ }^{16}$ In CKD patients, in contrast to hypertensive patients, there have been conflicting results in relation to GFR and AASI. In a cohort of 583 CKD patients, multivariate analyses have shown that AASI was independently correlated with renal function (serum cystatin C, GFR, serum creatinine), but no significant relationship with proteinuria was found. ${ }^{17}$ In contrast to this, in a study by Gismondi et al. AASI was not found to be correlated with urinary albumin/creatinine ratio, serum creatinine or GFR; however, it was significantly higher in the CKD group and was positively correlated with age and pulse pressure and inversely related to nocturnal blood pressure fall. ${ }^{18}$ Boesby et al. ${ }^{16}$ also did not find any significant correlation between AASI and GFR in patients with stage 2$5 \mathrm{CKD}$. We suggest that this phenomenon could be due to the deleterious effect of uremic toxins leading to the enhancement of atherosclerosis and arteriosclerosis and to the elevation of pulse pressure in parallel with similar effects caused by ageing. Wang et al. ${ }^{17}$ have identified an inverse correlation between GFR and AASI; however in this study, the average age of the studied CKD population was almost 20 years younger than in the two studies with negative findings. ${ }^{16,18}$ This theory is supported by a study by Gismondi et al. ${ }^{18}$ in which AASI showed a positive correlation with age. Furthermore, in the study by Boesby et al., ${ }^{16}$ AASI showed an inverse correlation with GFR, but this correlation disappeared after adjustment for age. In summary, it seems that an inverse correlation between AASI and GFR is present in younger CKD patients and disappears with aging, probably through the accelerated stiffening of the arteries leading to higher pulse pressure, which positively correlates with AASI.

In our recent study, we investigated children after kidney transplantation and found that the presence of hypertension, dipping state and lasting dialysis therapy were the main predictors of AASI. ${ }^{19}$ Furthermore, AASI was in the normal range in normotensive transplant patients, whereas PWV values were increased in this group and were similar to those of hypertensive children. PWV was increased in those children who spent more than 1 year in dialysis prior to transplantation. Hence, we suggest that AASI represents the dynamic relationship between daily systolic and diastolic blood pressure changes and that PWV, in contrast, reflects the long-term morphological changes of large arteries. ${ }^{19}$

One interventional follow-up study on CKD over 24 weeks has shown that the AASI values were unchanged by the aldosterone receptor inhibitor eplerenone. ${ }^{20}$

However, AASI has been criticized by some authors. Schillaci et al. ${ }^{21}$ have found only a weak association between AASI and PWV. Laurent has suggested that the hemodynamic significance of AASI is closer to that of brachial pulse pressure than that of arterial stiffness and defines AASI only as a surrogate measure of arterial stiffness. ${ }^{22}$ The potentially higher predictive value of aortic PWV than 'surrogate' indexes may explain why the predictive value of AASI for cardiovascular mortality and fatal stroke reported by Dolan et al. ${ }^{11}$ in the Dublin Outcome Study is lower than the predictive value reported for aortic PWV by others. ${ }^{23-25}$

Gavish has concluded that positive correlations between AASI and stiffness-related variables cannot confirm an association between AASI and arterial stiffness. ${ }^{26}$ According to the definition of AASI, the slope is determined by different blood pressure levels and is independent of the distribution of data along the regression line. In contrast, it is well-known that arterial stiffness increases with higher blood pressure levels, which makes it sensitive to the distribution of blood pressure data. ${ }^{26} \mathrm{~A}$ recent study has supported this difference between AASI and 
arterial stiffness parameters. In contrast to PWV, AASI has been found to be unchanged during blood pressure reduction one year after the initiation of antihypertensive medication. ${ }^{27}$ Because changes in cardio-ankle vascular index, another arterial stiffness parameter, over a 6-month serial-assessment period predict future cardiovascular events, ${ }^{28}$ the lack of change in AASI despite the clear reduction in cardiovascular risk resulting from blood pressure reduction probably signifies its limited predictive value.

Schillaci et al. have found that AASI is strongly dependent on the degree of nocturnal BP decrease in hypertensive patients, and they have suggested that the prognostic impact of AASI might, at least in part, depend on its association with a diminished nocturnal systolic and especially diastolic blood pressure fall. ${ }^{21}$ Westerhof et al. ${ }^{29}$ have mathematically deduced that AASI depends not only on the total arterial compliance or its inverse arterial stiffness, but also on the systemic vascular resistance, heart period and pressure. Therefore, increased arterial stiffness results in an increase in both AASI and pulse pressure. Consequently, AASI correlates with the indicators of arterial stiffness but is not a measure of arterial stiffness: it is a measure of ventriculo-arterial coupling. ${ }^{29}$

In conclusion, AASI is a promising method for the evaluation of the dynamic relationship between daily systolic and diastolic blood pressure changes. AASI seems to be useful in evaluating the risk of target organ damage in hypertensive patients, but it seems to be inappropriate for monitoring the effect of antihypertensive medication. In CKD, the results are conflicting as well. Whether AASI is comparable to PWV or is only a new surrogate measure of arterial stiffness is still questionable. It is unlikely that AASI will replace the gold standard tonometric methods in the near future.

\section{NEW METHODOLOGIES FOR 24-H ARTERIAL STIFFNESS MONITORING}

Just as the invention of ABPM elicited a revolution in blood pressure research and patient management since the end of the 1970s, the recently developed oscillometric $24-\mathrm{h}$ arterial stiffness and central blood pressure monitors may also evoke enthusiasm in the scientific community. In the following sections, we reviewed three available methodologies, Mobil-O-Graph, Vasotens and Arteriograph 24, and we summarize the results on different patient populations, particularly on CKD.

\begin{abstract}
Mobil-O-Graph
Mobil-O-Graph NG-ambulatory blood pressure monitor (NG-ABPM) by IEM, Stolberg, Germany, became commercially available in 2010. It uses the oscillometric method (ARCSolver algorithm) with an upper-arm blood pressure cuff. ${ }^{30}$ The standard cuff, inflated to just above the diastolic pressure, is used to record the brachial artery waveforms. Then, a generalized transfer function is applied to the averaged waveform to generate a corresponding aortic waveform, which is scaled to the recorded brachial diastolic and mean pressures. ${ }^{31}$ Comparing the Mobil-O-Graph with the gold standard tonometric SphygmoCor device, Wassertheurer et al. ${ }^{30}$ have found a mean difference in estimated aortic systolic blood pressure of only $0.1 \mathrm{~mm} \mathrm{Hg}$ and a difference in aortic Aix of 1.2\%. An acceptable accuracy between PWV measured by the Mobil-O-Graph and PWV derived from the invasive intra-aortic catheter measurements has been demonstrated, but the application of the oscillometric method resulted in moderately higher PWV values. ${ }^{32}$ Similarly to these findings, a very strong correlation has been found between the PWV values measured by the oscillometric device and those measured by cardiac magnetic resonance imaging, but the absolute PWV values were higher when
\end{abstract}

assessed by mathematical transformation of brachial waveforms. ${ }^{33}$ Using the oscillometric method above, Protogerau et al. ${ }^{34}$ have found that 24-h average aortic systolic blood pressure is better associated with ultrasound-measured left ventricular mass and left ventricular hypertrophy than the 24-h average brachial, office brachial or central systolic blood pressure in hypertensive patients independently of age, sex, obesity or treatment. Using the same method, similar results have been found upon examining the left ventricular diastolic dysfunction: 24-h aortic blood pressure was superior to other blood pressures. ${ }^{35}$ In 90 patients with obstructive apnea syndrome, apnea-hypopnea index was associated with the PWV and Aix measured by the Mobil-O-Graph device. ${ }^{36}$

There are already some studies available using Mobil-O-Graph to investigate arterial stiffness in CKD patients. Arterial stiffness values of 73 hemodialysis patients measured using the Mobil-O-Graph device have been compared with values measured using the SphygmoCor device. Whereas aortic systolic blood pressure and Aix exhibited acceptable agreement between the two devices, the measured values of PWV were significantly lower with the Mobil-O-Graph device. ${ }^{37}$ With the same device, Akdam et al. have found an increased PWV in CKD patients in stage 3B-5 compared with patients with continuous ambulatory peritoneal dialysis and to controls, whereas Aix values were similar among the three groups. Age, central systolic blood pressure, body mass index, fat mass, over-hydration, $\mathrm{CKD}$ and epidermal growth factor receptor were found to be the major determinants of PWV. ${ }^{38}$ Recently, Salvadé et al. ${ }^{39}$ have demonstrated in dialysis patients that Mobil-O-Graph PWV is more sensitive for vascular aging than pulse pressure, a recommended KDOQI cardiovascular risk-monitoring parameter.

In agreement with some authors who found no effect of hemodialysis on tonometric $\mathrm{PWV},{ }^{40,41}$ Karpetas et al. have demonstrated only a moderate increase in interdialytic PWV with Mobil-O-Graph, whereas interdialytic Aix showed a gradual increase. $^{42}$ In contrast to these findings, Koutroumbas et al. ${ }^{43}$ have recently demonstrated significantly higher aortic blood pressure, Aix and PWV levels with 72-h Mobil-O-Graph monitoring during the third interdialytic day compared with the second interdialytic day. However, because PWV changed only $0.2 \mathrm{~m} \mathrm{~s}^{-1}$ on average (from 9.4 to $9.6 \mathrm{~m} \mathrm{~s}^{-1}$ ), the clinical significance of this elevation is questionable. ${ }^{43}$ In the case of Aix, the consequently observed higher variability potential could have previously led to conflicting results in cardiovascular event prediction in ESRD with tonometric methods because in older dialysis patients with cardiovascular comorbidities Aix was a strong predictor, ${ }^{4}$ whereas it failed to be a strong predictor in younger patients. ${ }^{44} \mathrm{We}$ have also previously found in ESRD only that pre- and post-dialysis PWV and pre-dialysis carotid-brachial pulse pressure amplification, but not Aix, may have predictive value for cardiovascular mortality. ${ }^{45}$

Another study supporting and emphasizing the importance of pulse pressure amplification in CKD is the prospective follow-up study of Wassertheuer et al. using Mobil-O-Graph in 135 CKD patients. Compared with the controls, pulse pressure amplification was shown to be strongly reduced in CKD patients; it was associated with renal function and was able to predict renal endpoints (defined by $50 \%$ loss of renal function or the start of renal replacement therapy) in severe CKD. Aortic PWV and eGFR were not associated with pulse pressure amplification. ${ }^{46}$ In a paper from the same authors, in the same population, when PWV results were generated, the oscillometric PWV did not predict renal function, CKD progression or induction of dialysis, but appeared to be an independent predictor for all-cause mortality with a cutoff value of $10 \mathrm{~m} \mathrm{~s}^{-1.47}$ 
In summary, strong correlations and an acceptable accuracy of PWV values have been found with Mobil-O-Graph in comparison with invasive or magnetic resonance imaging methods, although moderate differences were found in the absolute values. Excellent parallel validation results have been described with respect to Aix and aortic systolic blood pressure compared with the SphygmoCor device. Moreover, 24-h aortic systolic blood pressure has been shown to be superior to 24-h brachial blood pressure in predicting target organ damage, such as left ventricular hypertrophy and ventricular diastolic dysfunction, in hypertensive patients. Although Mobil-O-Graph PWV values in $\mathrm{CKD}$ are significantly lower than those obtained with the SphygmoCor device, the device still predicts all-cause mortality independently with a cutoff value of $10 \mathrm{~m} \mathrm{~s}^{-1}$, whereas the pulse pressure amplification predicts renal end points. In addition, Mobil-O-Graph PWV is a better predictor of vascular aging than pulse pressure. This cumulating evidence shows that this methodology has potential for the improvement of risk stratification, but many questions remain. Can the recommended normal values of PWV and central blood pressure be automatically adopted for this oscillometric device? Do 24-h PWV and Aix values have any superiority over office PWV and Aix measurements in CKD? Can a validation study performed in a laboratory setting have any limitations compared with ambulatory, out-of-office data? Do nighttime aortic blood pressure changes have the same importance as brachial blood pressure dipping? Does the incidental presence of Mönckeberg sclerosis in CKD and ESRD cause any bias in the oscillometric 24-h PWV, Aix or central blood pressure measurements?

\section{Vasotens}

The operating principle of the recently developed Russian Vasotens device is based on the analysis of the ABPM waveforms by a special automatic mathematical algorithm that enables the calculation of central pulse wave parameters from the peripheral pulse wave. ${ }^{48}$ This method successfully passed reproducibility and repeatability tests for central aortic systolic blood pressure, reflected wave transit time and Aix. ${ }^{49}$ Comparing the Vasotens device with the widely accepted tonometric SphygmoCor showed that the measurements of central systolic and diastolic blood pressure, aortic Aix and PWV were in accordance on these devices. ${ }^{50}$ In the normotensive population, normal and reference values for indexes of Vasotens technology (Aix, PWV and central blood pressure) have been demonstrated by Kuznetsova et al., ${ }^{48}$ who found a significant nocturnal fall of PWV in all age groups, in both men and women. Interestingly, women had a significantly lower PWV than men in this study.

The new version of the Vasotens software automatically calculates the Pulse Time Index of Norm (PTIN), which is defined as the percentage of a 24-h period during which the PWV does not exceed the $10 \mathrm{~m} \mathrm{~s}^{-1}$ cutoff value for hypertensive target organ damage.
Reanalyzing 85 oscillometric-generated waveforms, Posokhov et al. ${ }^{51}$ have suggested that PTIN has an excellent day-to-day repeatability and internal consistency. A good correlation between PTIN and the left ventricular mass index has been demonstrated in hypertensive patients. ${ }^{52}$ A study by Minyukhina et al. ${ }^{53}$ has determined a cutoff value of PTIN that was set at $45 \%$ in CKD patients before and after kidney transplantation. In a group with an initial PTIN of $45 \%$ or higher, PTIN exhibited an interesting variability during follow-up; although it decreased during the first week, it increased again 20 weeks after the operation even when compared with the initial PTIN values. In the other group with an initial PTIN below $45 \%$, there were no significant changes. Thus, there appears to be a good chance that PTIN will exhibit long-term improvements after transplantation in patients with higher PTIN. ${ }^{53}$

In summary, Vasotens is another oscillometric device for the evaluation of the 24-h arterial stiffness and central blood pressure values. PTIN, which carries further information about the cardiovascular risk in hypertensive and CKD patients, can be considered a general parameter for all devices measuring 24-h arterial stiffness parameters. However, we propose that a parameter, an 'inverse PTIN', or 'Pulse Wave Index of Abnormality/Hazard' may be more demonstrative, showing the percentage of measurements above the target value, which could be decreased during interventions. We also argue that the $10 \mathrm{~m} \mathrm{~s}^{-1}$ cutoff value should be used for both the daytime and nighttime measurements of 24-h PWV; in mirroring the nocturnal fall, a reduced nighttime cutoff value might be considered. Clearly, many questions remain and more studies are required, particularly in reference to CKD.

\section{Arteriograph 24}

The last device that we will discuss is the commercially available Hungarian Arteriograph 24. It was developed by TensioMed (Budapest, Hungary) and is based on the methodology used in the oscillometric Arteriograph. In brief, it simultaneously measures peripheral and aortic systolic blood pressure, aortic Aix and PWV through an upper-arm cuff connected to a piezoelectric sensor. Although the cuff is pressurized at least $35 \mathrm{~mm} \mathrm{Hg}$ over the actual systolic blood pressure, the sensor picks up pulse wave signals and the software determines the central blood pressure and arterial stiffness values. The distance measurement used in the PWV calculation is between the jugulum and symphysis, suggesting a fixed reflection point above the aortic bifurcation. ${ }^{54}$ Validation studies comparing Arteriograph and the gold standard methods are already available, and an invasive validation study has also been published. ${ }^{54-58}$ In spite of the good correlation coefficients, most of the authors have concluded that the arterial stiffness values of the different devices are not interchangeable, and follow-up studies are required to show the prognostic value of Arteriograph parameters. ${ }^{56-59}$ In a recent

Table 2 Comparison of the three available 24-h arterial stiffness monitors (references)

\begin{tabular}{|c|c|c|c|}
\hline Device & Mobil-O-Graph & Vasotens & Arteriograph 24 \\
\hline Method & Oscillometric & Oscillometric & Oscillometric \\
\hline Number of publications on PubMed & $34^{30-39,42,43,46,47}$ & $7^{48-53}$ & $1^{66, a}$ \\
\hline Validation data of the methodology is available with & SphygmoCor, intra-aortic catheter measurement, $\mathrm{MRI}^{30,32,33}$ & SphygmoCor ${ }^{50}$ & No data are available ${ }^{b}$ \\
\hline $\begin{array}{l}\text { Predictive value of the PWV measured with the } \\
\text { methodology }\end{array}$ & $\begin{array}{l}\text { Renal endpoints and all-cause mortality in CKD } \\
\text { (office measurement) } 46,47\end{array}$ & No data are available & No data are available ${ }^{c}$ \\
\hline
\end{tabular}

aWith Arteriograph 24, 75 publications with Arteriograph.

bWith Arteriograph: SphygmoCor, Complior, invasive measurement.

With Arteriograph: CV events after MI, mortality in advanced heart failure. 
validation study, only poor correlations were found between Arteriograph, Complior and Echo-tracking methods, and the authors emphasized the establishment of PWV reference values for each of these techniques. ${ }^{60}$ To date, three follow-up studies aimed at evaluating the predictive strength of Arteriograph stiffness parameters for cardiovascular events or mortality are available. Akkus et al. ${ }^{61}$ have demonstrated that the PWV and Aix values of Arteriograph can predict further cardiovascular events in patients after myocardial infarction, and Demir et al. ${ }^{62}$ have shown mortality prediction in advanced heart failure with the cutoff value of $11 \mathrm{~m} \mathrm{~s}^{-1}$ for PWV. One follow-up study with cardiovascular endpoints in CKD patients is available, in which we demonstrated the lack of prognostic value of Arteriograph PWV and Aix for cardiovascular mortality in ESRD patients on hemodialysis. ${ }^{63}$ Another follow-up study on kidney transplant patients has shown the parallel progression of Arteriograph-measured PWV and carotid artery sclerosis over a period of 3 years. ${ }^{64}$ Finally, in hemodialysis patients, a $1 \mathrm{~m} \mathrm{~s}^{-1}$ decrease in PWV with a simultaneous $10 \mathrm{~mm} \mathrm{Hg}$ decrease in central blood pressure has been found to be the effect of a 3-month long 40-min training exercise during hemodialysis sessions. ${ }^{65}$

There are already numerous publications using Arteriograph; however, there is only one manuscript featuring Arteriograph 24 that is available on PubMed to date. The manuscript featuring Arteriograph 24 shows that gout patients with CKD have a significantly worse 24-h Aix compared with gout patients without CKD. ${ }^{66}$

In summary, Arteriograph 24 is the third oscillometric device using the methodology of Arteriograph. Arteriograph 24 shows promise, but will require more data concerning the predictive value for cardiovascular events and mortality in broader patient populations. Moreover, we question whether the validation studies performed with Arteriograph can automatically be generalized for Arteriograph 24; therefore, validation, cross-sectional and follow-up data are still required for evaluating the utility of Arteriograph 24 parameters. Another critical question about this methodology is the amount of bias causing the change of the theoretically constant reflection point used in PWV measurements during sitting, standing or supine positions in a 24-h period. One paper seeking to clarify this issue has found good correlations between Arteriograph PWV and Aix values in sitting and supine positions. ${ }^{67}$

In Table 2, we provide a short comparison of the three oscillometric devices. An important question about these devices is whether a clinical result that is demonstrated with one device can be universalized for all of them. This is a problem with more prevalent arterial stiffness parameters as well, as it has recently been demonstrated that the ARB valsartan reduces only carotid-femoral PWV but not brachial-ankle PWV. ${ }^{68}$ Therefore, comparative studies with these oscillometric monitors are required.

\section{CONCLUSIONS}

In the past two decades, the evaluation of arterial stiffness with PWV as the most widely accepted parameter has been recognized as an independent predictor of cardiovascular risk and mortality, especially in CKD and ESRD. Ambulatory arterial stiffness measurement methodologies may open a new field of research and, hopefully, will improve cardiovascular risk stratification in the future. AASI derived from ambulatory blood pressure measurements was introduced in 2006. Despite this fact, the data accumulated since that time have not been convincing enough for this parameter to be included in the guidelines or for it to be used widely in everyday patient management. The invention of new oscillometric 24-h monitors that, in addition to their ABPM function, provide arterial stiffness and central blood pressure data, may have a significant impact in the future. However, only in the case of Mobil-O-Graph has it been demonstrated that 24-h aortic blood pressure is superior to office brachial or central blood pressure data in the prediction of target organ damage in hypertensive patients. ${ }^{34,35}$ Although clinical data are accumulating, we are still far from understanding the real relevance of these new devices in cardiovascular risk stratification, and many questions remain.

\section{CONFLICT OF INTEREST}

The authors declare no conflict of interest.

\section{ACKNOWLEDGEMENTS}

We acknowledge the contribution of Oleg Pogrebnyak for his technical and linguistic support.

1 Wheeler DC. Cardiovascular disease in patients with chronic renal failure. Lancet 1996; 348: 1673-1674.

2 Collins AJ. Cardiovascular mortality in end-stage renal disease. Am J Med Sci 2003; 325: 163-167.

3 Blacher J, Guerin AP, Pannier B, Marchais SJ, Safar ME, London GM. Impact of aortic stiffness on survival in end-stage renal disease. Circulation 1999; 99: 2434-2439.

4 London GM, Blacher J, Pannier B, Guerin AP, Marchais SJ, Safar ME. Arterial wave reflections and survival in end-stage renal failure. Hypertension 2001; 38: 434-438.

5 Nemcsik J, Kiss I, Tisler A. Arterial stiffness, vascular calcification and bone metabolism in chronic kidney disease. World J Nephrol 2012; 1: 25-34.

6 Laurent S, Mousseaux E, Boutouyrie P. Arterial stiffness as an imaging biomarker: are all pathways equal? Hypertension 2013; 62: 10-12.

7 Mancia G, Fagard R, Narkiewicz K, Redon J, Zanchetti A, Böhm M, Christiaens T, Cifkova R, De Backer G, Dominiczak A, Galderisi M, Grobbee DE, Jaarsma T, Kirchhof P, Kjeldsen SE, Laurent S, Manolis AJ, Nilsson PM, Ruilope LM, Schmieder RE, Sirnes PA, Sleight P, Viigimaa M, Waeber B, Zannad F, Redon J, Dominiczak A, Narkiewicz K, Nilsson PM, Burnier M, Viigimaa M, Ambrosioni E, Caufield $M$, Coca $A$, Olsen $M H$, Schmieder RE, Tsioufis $C$, van de Borne $P$, Zamorano JL, Achenbach S, Baumgartner H, Bax JJ, Bueno H, Dean V, Deaton C, Erol C, Fagard R, Ferrari R, Hasdai D, Hoes AW, Kirchhof P, Knuuti J, Kolh P, Lancellotti P, Linhart A, Nihoyannopoulos P, Piepoli MF, Ponikowski P, Sirnes PA, Tamargo JL, Tendera M, Torbicki A, Wijns W, Windecker S, Clement DL, Coca A, Gillebert TC, Tendera M, Rosei EA, Ambrosioni E, Anker SD, Bauersachs J, Hitij JB, Caulfield M, De Buyzere M, De Geest S, Derumeaux GA, Erdine S, Farsang C, Funck-Brentano C, Gerc V, Germano G, Gielen S, Haller H, Hoes AW, Jordan J, Kahan T, Komajda M, Lovic D, Mahrholdt H, Olsen MH, Ostergren J, Parati G, Perk J, Polonia J, Popescu BA, Reiner Z, Rydén L, Sirenko Y, Stanton A, Struijker-Boudier H, Tsioufis C, van de Borne P, Vlachopoulos C, Volpe M, Wood DA. 2013 ESH/ESC guidelines for the management of arterial hypertension: the Task Force for the Management of Arterial Hypertension of the European Society of Hypertension (ESH) and of the European Society of Cardiology (ESC). Eur Heart J 2013; 34: 2159-2219.

8 Li Y, Wang JG, Dolan E, Gao PJ, Guo HF, Nawrot T, Stanton AV, Zhu DL, O'Brien E, Staessen JA. Ambulatory arterial stiffness index derived from 24-h ambulatory blood pressure monitoring. Hypertension 2006; 47: 359-364.

9 Leoncini G, Ratto E, Viazzi F, Vaccaro V, Parodi A, Falqui V, Conti N, Tomolillo C, Deferrari G, Pontremoli R. Increased ambulatory arterial stiffness index is associated with target organ damage in primary hypertension. Hypertension 2006; 48: 397-403.

10 García-García A, Gómez-Marcos MA, Recio-Rodriguez JI, González-Elena LJ, Parra-Sanchez J, Fe Muñoz-Moreno M, Alonso CP, Gude F, García-Ortiz L. Relationship between ambulatory arterial stiffness index and subclinical target organ damage in hypertensive patients. Hypertens Res 2011; 34: 180-186.

11 Dolan E, Thijs L, Li Y, Atkins N, McCormack P, McClory S, O'Brien E, Staessen JA, Stanton AV. Ambulatory arterial stiffness index as a predictor of cardiovascular mortality in the Dublin Outcome Study. Hypertension 2006; 47: 365-370.

12 Muxfeldt ES, Cardoso CR, Dias VB, Nascimento AC, Salles GF. Prognostic impact of the ambulatory arterial stiffness index in resistant hypertension. J Hypertens 2010; 28 : 1547-1553.

13 Kikuya M, Staessen JA, Ohkubo T, Thijs L, Metoki H, Asayama K, Obara T, Inoue R, Li Y, Dolan E, Hoshi H, Hashimoto J, Totsune K, Satoh H, Wang JG, O'Brien E, Imai Y. Ambulatory arterial stiffness index and 24-h ambulatory pulse pressure as predictors of mortality in Ohasama, Japan. Stroke 2007; 38: 1161-1166.

14 Mulè $G$, Cottone $S$, Cusimano $P$, Incalcaterra $F$, Giandalia $M$, Costanzo $M$, Nardi $E$, Palermo A, Geraci C, Costa R, Cerasola G. Inverse relationship between ambulatory arterial stiffness index and glomerular filtration rate in arterial hypertension. Am J Hypertens 2008; 21: 35-40.

15 Ratto E, Leoncini G, Viazzi F, Vaccaro V, Falqui V, Parodi A, Conti N, Tomolillo C, Deferrari G, Pontremoli R. Ambulatory arterial stiffness index and renal abnormalities in primary hypertension. J Hypertens 2006; 24: 2033-2038. 
16 Boesby L, Thijs L, Elung-Jensen T, Strandgaard S, Kamper AL. Ambulatory arterial stiffness index in chronic kidney disease stage 2-5. Reproducibility and relationship with pulse wave parameters and kidney function. Scand J Clin Lab Invest 2012; 72 304-312.

17 Wang C, Zhang J, Li CC, Gong WY, Liu X, Ye ZC, Peng H, Lou TQ. The ambulatory arterial stiffness index and target-organ damage in Chinese patients with chronic kidney disease. BMC Nephrol 2013; 14: 257.

18 Gismondi RA, Neves MF, Oigman W, Bregman R. Ambulatory arterial stiffness index is higher in hypertensive patients with chronic kidney disease. Int J Hypertens 2012; 2012: 178078.

19 Dégi A, Kerti A, Cseprekál O, Kis É, Sallay P, Szabó AJ, Reusz GS. Ambulatory arterial stiffness index in children after kidney transplantation. Pediatr Transplant 2013; 17 598-604.

20 Boesby L, Elung-Jensen T, Strandgaard S, Kamper AL. Eplerenone attenuates pulse wave reflection in chronic kidney disease stage 3-4-a randomized controlled study. PLoS ONE 2013; 8: e64549.

21 Schillaci G, Parati G, Pirro M, Pucci G, Mannarino MR, Sperandini L, Mannarino E. Ambulatory arterial stiffness index is not a specific marker of reduced arterial compliance. Hypertension 2007; 49: 986-991.

22 Laurent S. Surrogate measures of arterial stiffness: do they have additive predictive value or are they only surrogates of a surrogate? Hypertension 2006; 47: 325-326.

23 Cruickshank K, Riste L, Anderson SG, Wright JS, Dunn G, Gosling RG. Aortic pulse-wave velocity and its relationship to mortality in diabetes and glucose intolerance: an integrated index of vascular function? Circulation 2002; 106: 2085-2090.

24 Laurent S, Boutouyrie P, Asmar R, Gautier I, Laloux B, Guize L, Ducimetiere P, Benetos A. Aortic stiffness is an independent predictor of all-cause and cardiovascular mortality in hypertensive patients. Hypertension 2001; 37: 1236-1241.

25 Laurent S, Katsahian S, Fassot C, Tropeano Al, Gautier I, Laloux B, Boutouyrie P. Aortic stiffness is an independent predictor of fatal stroke in essential hypertension. Stroke 2003; 34: 1203-1206.

26 Gavish B. Correlating ambulatory blood pressure measurements with arterial stiffness: a conceptual inconsistency? Hypertension 2006; 48: e108; author reply e109.

27 Kollias A, Rarra V, Karpettas N, Roussias L, O'Brien E, Stergiou GS. Treatment-induced changes in ambulatory arterial stiffness index: one-year prospective study and meta-analysis of evidence. Hypertens Res 2015; 38: 627-631.

28 Otsuka K, Fukuda S, Shimada K, Suzuki K, Nakanishi K, Yoshiyama M, Yoshikawa J. Serial assessment of arterial stiffness by cardio-ankle vascular index for prediction of future cardiovascular events in patients with coronary artery disease. Hypertens Res 2014; 37: 1014-1020.

29 Westerhof N, Lankhaar JW, Westerhof BE. Ambulatory arterial stiffness index is not a stiffness parameter but a ventriculo-arterial coupling factor. Hypertension 2007; 49: e7; author reply e8-9.

30 Wassertheurer S, Kropf J, Weber T, van der Giet M, Baulmann J, Ammer M, Hametner B, Mayer CC, Eber B, Magometschnigg D. A new oscillometric method for pulse wave analysis: comparison with a common tonometric method. J Hum Hypertens 2010; 24: 498-504.

31 Wilkinson IB, McEniery CM, Cockcroft JR. Central blood pressure estimation for the masses moves a step closer. J Hum Hypertens 2010; 24: 495-497.

32 Hametner B, Wassertheurer S, Kropf J, Mayer C, Eber B, Weber T. Oscillometric estimation of aortic pulse wave velocity: comparison with intra-aortic catheter measurements. Blood Pressure Monit 2013; 18: 173-176.

33 Feistritzer HJ, Reinstadler SJ, Klug G, Kremser C, Seidner B, Esterhammer R, Schocke MF, Franz WM, Metzler B. Comparison of an oscillometric method with cardiac magnetic resonance for the analysis of aortic pulse wave velocity. PLOS ONE 2015; 10: e0116862.

34 Protogerou AD, Argyris AA, Papaioannou TG, Kollias GE, Konstantonis GD, Nasothimiou E, Achimastos A, Blacher J, Safar ME, Sfikakis PP. Left-ventricular hypertrophy is associated better with 24-h aortic pressure than 24-h brachial pressure in hypertensive patients: the SAFAR study. J Hypertens 2014; 32: 1805-1814.

35 Zhang Y, Kollias G, Argyris AA, Papaioannou TG, Tountas C, Konstantonis GD, Achimastos A, Blacher J, Safar ME, Sfikakis PP, Protogerou AD. Association of left ventricular diastolic dysfunction with 24-h aortic ambulatory blood pressure: the SAFAR study. J Hum Hypertens 2015; 7: 442-448.

36 Çörtük M, Akyol S, Baykan AO, Kiraz K, Uçar H, Çaylı M, Kandiş H. Aortic stiffness increases in proportion to the severity of apnoea-hypopnea index in patients with obstructive sleep apnoea syndrome. Clin Respir J (e-pub ahead of print 23 December 2014; doi:10.1111/crj.12244).

37 Sarafidis PA, Georgianos PI, Karpetas A, Bikos A, Korelidou L, Tersi M, Divanis D, Tzanis G, Mavromatidis K, Liakopoulos V, Zebekakis PE, Lasaridis A, Protogerou AD. Evaluation of a novel brachial cuff-based oscillometric method for estimating central systolic pressure in hemodialysis patients. Am J Nephrol 2014; 40 242-250.

38 Akdam H, Öğünç H, Alp A, Özbek Ö, Ömürlü IK, Yeniçerioğlu Y, Akar H. Assessment of volume status and arterial stiffness in chronic kidney disease. Ren Fail 2014; 36 28-34.

39 Salvadé I, Schätti-Stählin S, Violetti E, Schönholzer C, Cereghetti C, Zwahlen H, Berwert L, Burnier M, Gabutti L. A prospective observational study comparing a non-operator dependent automatic PWV analyser to pulse pressure, in assessing arterial stiffness in hemodialysis. BMC Nephrol 2015; 16: 62.

40 Reising A, Sambale S, Donnerstag F, Schmidt JJ, Hafer C, Schmidt BM, Kielstein JT. Effect of isovolemic, isothermic hemodialysis on cerebral perfusion and vascular stiffness using contrast computed tomography and pulse wave velocity. PLOS ONE 2013; 8: e56396.
41 Georgianos PI, Sarafidis PA, Malindretos P, Nikolaidis P, Lasaridis AN. Hemodialysis reduces augmentation index but not aortic or brachial pulse wave velocity in dialysis-requiring patients. Am J Nephrol 2011; 34: 407-414.

42 Karpetas A, Sarafidis PA, Georgianos PI, Protogerou A, Vakianis P, Koutroumpas G, Raptis V, Stamatiadis DN, Syrganis C, Liakopoulos V, Efstratiadis G, Lasaridis AN. Ambulatory recording of wave reflections and arterial stiffness during intra- and interdialytic periods in patients treated with dialysis. Clin J Am Soc Nephrol 2015; 10 630-638.

43 Koutroumbas G, Georgianos PI, Sarafidis PA, Protogerou A, Karpetas A, Vakianis $P$, Raptis V, Liakopoulos V, Panagoutsos $S$, Syrganis C, Passadakis $P$. Ambulatory aortic blood pressure, wave reflections and pulse wave velocity are elevated during the third in comparison to the second interdialytic day of the long interval in chronic haemodialysis patients. Nephrol Dialy Transplant 2015; pii: gfv09

44 Covic A, Mardare N, Gusbeth-Tatomir P, Prisada O, Sascau R, Goldsmith DJ. Arterial wave reflections and mortality in haemodialysis patients-only relevant in elderly, cardiovascularly compromised? Nephrol Dial Transplant 2006; 21 2859-2866

45 Othmane Tel H, Nemcsik J, Fekete BC, Deák G, Egresits J, Fodor E, Logan AG, Németh ZK, Járai Z, Szabó T, Szathmári M, Kiss I, Tislér A. Arterial stiffness in hemodialysis: which parameter to measure to predict cardiovascular mortality? Kidney Blood Press Res 2009; 32: 250-257.

46 Wassertheurer S, Burkhardt K, Heemann U, Baumann M. Aortic to brachial pulse pressure amplification as functional marker and predictor of renal function loss in chronic kidney disease. J Clin Hypertens (Greenwich) 2014; 16: 401-405.

47 Baumann M, Wassertheurer S, Suttmann Y, Burkhardt K, Heemann U. Aortic pulse wave velocity predicts mortality in chronic kidney disease stages 2-4. J Hypertens 2014; 32: 899-903.

48 Kuznetsova TY, Korneva VA, Bryantseva EN, Barkan VS, Orlov AV, Posokhov IN, Rogoza AN. BPLab-Vasotens registry collaborators. The 24-h pulse wave velocity, aortic augmentation index, and central blood pressure in normotensive volunteers. Vasc Health Risk Manag 2014; 10: 247-251.

49 Ageenkova OA, Purygina MA. Central aortic blood pressure, augmentation index, and reflected wave transit time: reproducibility and repeatability of data obtained by oscillometry. Vasc Health Risk Manag 2011; 7: 649-656.

50 Kotovskaya YV, Kobalava ZD, Orlov AV. Validation of the integration of technology that measures additional 'vascular' indices into an ambulatory blood pressure monitoring system. Med Devices (Auckl) 2014; 7: 91-97.

51 Posokhov IN, Konradi AO, Shlyakhto EV, Mamontov OV, Orlov AV, Rogoza AN. Day-to-day repeatability of the Pulse Time Index of Norm. Med Devices (Auckl) 2014; 7: 29-33.

52 Posokhov IN, Kulikova NN, Starchenkova IV, Grigoricheva EA, Evdokimov VV, Orlov AV, Rogoza AN. BPLab-Vasotens Registry Collaborators. The 'Pulse Time Index of Norm' highly correlates with the left ventricular mass index in patients with arterial hypertension. Vasc Health Risk Manag 2014; 10: 139-144.

53 Minyukhina IE, Lipatov KS, Posokhov IN. Analysis of 24-h pulse wave velocity in patients with renal transplantation. Int J Nephrol Renovasc Dis 2013; 6: 125-129.

54 Horváth IG, Németh A, Lenkey Z, Alessandri N, Tufano F, Kis P, Gaszner B, Cziráki A. Invasive validation of a new oscillometric device (Arteriograph) for measuring augmentation index, central blood pressure and aortic pulse wave velocity. $J$ Hypertens 2010; 28: 2068-2075.

55 Baulmann J, Schillings U, Rickert S, Uen S, Düsing R, Illyes M, Cziraki A, Nickering G, Mengden T. A new oscillometric method for assessment of arterial stiffness: comparison with tonometric and piezo-electronic methods. J Hypertens 2008; 26: 523-528.

56 Jatoi NA, Mahmud A, Bennett K, Feely J. Assessment of arterial stiffness in hypertension: comparison of oscillometric (Arteriograph), piezoelectronic (Complior) and tonometric (SphygmoCor) techniques. J Hypertens 2009; 27: 2186-2191.

57 van Dijk SC, Enneman AW, Swart KM, van Schoor NM, Uitterlinden AG, Smulders YM, van den Meiracker AH, van der Velde N, Mattace-Raso FU. Oscillometry and applanation tonometry measurements in older individuals with elevated levels of arterial stiffness. Blood Press Monit 2013; 18: 332-338.

58 Rajzer MW, Wojciechowska W, Klocek M, Palka I, Brzozowska-Kiszka M, KaweckaJaszcz K. Comparison of aortic pulse wave velocity measured by three techniques: Complior, SphygmoCor and Arteriograph. J Hypertens 2008; 26: 2001-2007.

59 Parati G, De Buyzere M. Evaluating aortic stiffness through an arm cuff oscillometric device: is validation against invasive measurements enough? J Hypertens 2010; 28 2003-2006.

60 Mihalcea DJ, Florescu M, Suran BM, Enescu OA, Mincu RI, Magda S, Patrascu N, Vinereanu D. Comparison of pulse wave velocity assessed by three different techniques: Arteriograph, Complior, and Echo-tracking. Heart Vessels (e-pub ahead of print 30 January 2015; doi:10.1007/s00380-015-0632-x).

61 Akkus O, Sahin DY, Bozkurt A, Nas K, Ozcan KS, Illyés M, Molnár F, Demir S, Tüfenk M, Acarturk E. Evaluation of arterial stiffness for predicting future cardiovascular events in patients with ST segment elevation and non-ST segment elevation myocardial infarction. ScientificWorldJournal 2013; 2013: 792693.

62 Demir S, Akpınar O, Akkus O, Nas K, Unal I, Molnar F, Demir A, Illyés M, Acartürk E. The prognostic value of arterial stiffness in systolic heart failure. Cardiol J 2013; 20: 665-671.

63 Nemcsik J, Egresits J, El Hadj Othmane T, Fekete BC, Fodor E, Szabó T, Járai Z, Jekkel C, Kiss I, Tislér A. Validation of arteriograph - a new oscillometric device to measure arterial stiffness in patients on maintenance hemodialysis. Kidney Blood Press Res 2009; 32: 223-229. 
64 Kovács D, Lőcsey L, Laczik R, Szabó L, Zsom L, Kabai K, Fedor R, Nemes B, Asztalos L, Soltész P. Three-year longitudinal clinical trial of arterial function assessed by a oscillometric non-invasive method in comparison with carotid sclerosis and transferrin kidney-transplanted patients. Transplant Proc 2014; 46: 2168-2170.

65 Mihaescu A, Avram C, Bob F, Gaita D, Schiller O, Schiller A. Benefits of exercise training during hemodialysis sessions: a prospective cohort study. Nephron Clin Pract 2013; 124: 72-78
66 Celik G, Yilmaz S, Kebapcilar L, Gundogdu A. Central arterial characteristics of gout patients with chronic kidney diseases. Int J Rheum Dis (e-pub ahead of print 14 July 2014; doi:10.1111/1756-185X.12689).

67 Nurnberger J, Michalski R, Turk TR, Opazo Saez A, Witzke O, Kribben A. Can arterial stiffness parameters be measured in the sitting position? Hypertens Res 2011; 34: 202-208.

68 Peng F, Pan H, Wang B, Lin J, Niu W. The impact of angiotensin receptor blockers on arterial stiffness: a meta-analysis. Hypertens Res 2015; 38: 613-620. 